\title{
Nurses' experiences of caring for the suddenly bereaved in adult acute and critical care settings, and the provision of person-centred care: A qualitative study
}

\section{ABSTRACT}

Aim: To explore nursing interventions for person-centred bereavement care in adult acute and critical care settings.

Design: A descriptive exploratory study, involving focused, face-to-face interviews. Participants comprised nine registered nurses and one auxiliary nurse, working in environments where sudden death was known to occur, i.e. emergency, cardiac and critical care. Interviews were transcribed verbatim and data subjected to directed content analysis. The provision of person-centred care was examined by applying a validated Person-Centred Nursing Framework.

Findings: Five main themes were identified. Participants' accounts contained descriptions of bereavement care and the presence of person-centred interventions. Contextual, professional and attitudinal factors influenced the degree to which personcentred care operated.

Conclusion: Caring for suddenly bereaved families was important to nurses, but also a source of tension and unrest. An important consideration for person-centred practice is movement away from sudden bereavement as a 'here and now' event, towards a pathway of supportive care that envisions the longer-term. Further research is required to gain a deeper understanding of person-centred care for the suddenly bereaved and the perceived effectiveness of nursing interventions. 
Keywords: Death, end-of-life, family, nurses, person-centred care, qualitative research, sudden bereavement

\section{Introduction}

In recent years, the nature and provision of end-of-life care (EoLC) for the dying and bereaved has become the focus of national service improvement in the United Kingdom (UK) (DH, 2008; LACDP, 2014, NCPC, 2014). Despite growing regard for community care and a non-institutional death, the majority of all deaths take place in hospital [58\%] and this figure is predicted to rise to around 65\% by 2030 (Leadbeater and Garber, 2010). For acute and critical care nurses, the death of a patient may be sudden following a life-threatening illness or event. A sudden death is generally $\leq 1$ hour from the onset of symptoms (Zipes and Wellens, 1998), although a 24-hr definition may be used if the death was unwitnessed and the victim was known to be alive and functioning normally prior to being found (Myerburg and Wellens, 2005). Williams et al. (2003) also described sudden or unexpected death with less than six weeks of warning in the context of intensive care.

The reality of a sudden death can be challenging for the experiencing family (Worden, 2009) and for the healthcare professionals involved (Purves and Edwards, 2005). Families are bereft of preparation and the resultant grief may be more pronounced (Deranieri et al., 2002) and prolonged (Kent and McDowell, 2004). Nurses are in a unique position to meet the needs of the suddenly bereaved and skilled interventions are essential for healthy adaptation (Walker, 2010). Quality Standards for End of Life Care for Adults (statements 7 and 14) emphasise the importance of 
timely support, appropriate to the needs and preferences of those closely affected by death (NICE, 2011). Person-centred care is a core component of UK health care policy that places patients and families at the centre of care decisions ( $\mathrm{DH}, 2010 ; \mathrm{DH}, 2012$ ). It has the potential to enhance the care experiences of the dying and bereaved (Ball et al., 2013), yet little is known about its application in the context of care for the suddenly bereaved.

Research to support the caring practices of acute and critical care staff who encounter sudden death and bereavement is scarce. The evidence base of research published in the last decade (2005-2015) is limited to a small number of published studies specific to the experiences of suddenly bereaved families (Brysiewicz, 2008; Dale et al., 2013; Rejnö et al., 2013; Rodger et al., 2006). Research into the needs of the suddenly bereaved is both sparse and dated (Fanslow, 1983; Fraser and Atkins, 1990; Li et al., 2002; Tye, 1993). This also applies to existing studies of qualified nurses' experiences of caring for the suddenly bereaved (Saines, 1997a; Saines, 1997b; Socorro et al., 2001). Despite an evolving body of research into intensive care nurses' experiences of providing EoLC, the phenomenon of sudden death and bereavement is typically implied. A marked absence of up-to-date research, with qualified nurses in the UK, and beyond the environment of accident and emergency (A\&E) underlined the need for further inquiry.

The overall aim of this study was to explore nursing interventions for personcentred bereavement care in adult acute and critical care settings. Specific objectives were to:

1. Provide insight into nurses' experiences of care for the suddenly bereaved; 
2. Examine the provision of person-centred bereavement care;

3. Inform the development of person-centredness in practice.

\section{Methods}

The study employed a descriptive exploratory design, suitable for investigating littleunderstood phenomena (Marshall and Rossman, 1999). The research setting was an inner-city hospital providing acute and critical care services. Purposive sampling gave preference to Registered Nurses (RNs) working in environments where sudden death was known to occur, i.e. emergency, cardiac and critical care. A Divisional Matron for each environment of care identified eligible participants on behalf of the Principal Investigator (PI). In the UK, employees are placed on one of nine pay bands using a job evaluation scheme that determines the pay band for each post. This system, known as Agenda for Change (NHS Employers, 2015), was used to identify a sample of participants with variable levels of knowledge, skills and responsibility, as determined by their pay band and associated post. Eighteen RNs received a letter of invitation, an information sheet and a reply slip for completion if willing to participate in the study. The aim was to recruit 12-18 RNs to participate in a focused, face-to-face group interview, comprising 4-6 people in each group.

\section{Participants}

A total of nine RNs, employed in pay bands 5-7 and working in the posts of Staff Nurse, Sister or Senior Sister were recruited to the study. An Auxiliary Nurse (pay band 3) with experience in emergency care requested participation, and this was facilitated. 
Participants were representative of each environment of care; emergency care $(n=4)$, critical care $(n=4)$ and cardiac care $(n=2)$. Characteristics of the study sample are shown in Table 1.

Table 1 Sample characteristics

\begin{tabular}{lllll}
\hline $\begin{array}{l}\text { Environment of care } \\
\text { No. of participants }\end{array}$ & A\&E & ICCU & CSW & CW \\
& 4 & 4 & 1 & 1 \\
Pay & Band 3 & Band 5 & Band 6 & Band 7 \\
No. of participants & 1 & 4 & 3 & 2 \\
& Auxiliary & Staff Nurse & Sister & Senior Sister \\
Post & 1 & 4 & 3 & 2 \\
No. of participants & \multicolumn{4}{l}{} \\
\hline $\begin{array}{l}\text { A\&E, Accident and Emergency } \\
\text { ICCU, Integrated Critical Care Unit (General and Cardiothoracic) }\end{array}$ \\
$\begin{array}{l}\text { CSW, Cardiothoracic Surgical Ward } \\
\text { CW, Cardiology Ward }\end{array}$
\end{tabular}

\section{Data collection}

An on-site hospital venue, suitable for group interaction was selected. The intended structure of the group interviews was affected by recruitment to the study and participant attendance. Data were ultimately collected face-to-face via two group interviews comprising three and four participants respectively, an interview involving two participants, and a one-to-one interview. The PI (WW) and a co-researcher (KD) jointly facilitated the two group interviews; WW led the discussion and KD monitored the interaction, dynamics and synergy of the group. A focused interview topic guide provided structure to the discussion. All interviews were audio-recorded with participants' consent. 


\section{Data analysis}

A debriefing session involving the PI and co-researcher took place after each group interview. On both occasions, there was shared recall of key points raised by the interviewees. All interviews were transcribed verbatim and data subjected to directed content analysis (Hsieh and Shannon, 2005). The provision of person-centred care was examined by selecting attributes of a Person-Centred Nursing Framework (McCormack and McCance, 2010) for the coding of material. Meaning was derived from the data by concentrating on five care processes and associated activities for person-centred nursing: 'working with patient's beliefs and values; engagement; having sympathetic presence; sharing decision making; and providing holistic care' (McCormack and McCance, 2010, p.37). Analyses commenced with line-by-line coding of data to identify salient issues. Coded data was initially assembled into 12 sub-themes on the basis of related content, and subsequently grouped to form five main themes that encompassed the study findings as a whole (Table 2). Themes 1-4 each contained descriptions of bereavement care activities and the presence of person-centredness. The final theme contained descriptions of factors influencing the provision of personcentred care.

\section{Ethical considerations}

Ethical conduct in respect of gaining participant consent included the provision of explicit information about the research. Confidentiality and anonymity of data was stressed, and maintained. Participants were given the option to withdraw from the study at any stage without prejudice. Written consent was obtained from each 
participant immediately prior to the interview. As part of this process, the interviewer (WW) discussed how the interview would proceed and responded to questions that arose. Permission to conduct the study was obtained from the Chief Nursing Officer and the Research and Development department at the participating hospital. The study was approved by the authors' University Ethics Committee.

Table 2 Thematic representation of the study findings

Main themes

\section{Sub-themes}

1. The context of care The meaning of sudden death A challenging situation

2. Perceived needs Information Comfort measures

3. Care provision Essential tasks Participation and choice

4. Beyond the event Supporting staff Supporting bereaved families Obtaining feedback

5. Influencing factors

Contextual

Professional

Attitudinal

\section{Findings}

\section{The context of care}

All participants were able to recall situations when they had cared for a suddenly bereaved family. Some questioned the meaning of sudden death and argued that this was circumstantial. For example, they suggested the death of a patient could be considered sudden if it happened on admission, after a short or long stay, subsequent 
to an abrupt deterioration and/or following planned withdrawal of treatment. Their accounts portrayed an overarching sense of unexpectedness. The families' interpretation of what constituted suddenness was advocated.

We might be expecting it because ... we've seen the downward trend over the last three days or whatever, but the family might not be expecting it. (I: (Interviewee) 06)

To me, anything would be sudden really. If I didn't want it to happen then it would be sudden ... It depends how the families feel about it. It's not really what I would class it as. It's what the family would class it as. (I:02)

Factors such as the mode and circumstances surrounding the death, managing the families' expectations, dealing with intra-family conflict and breaking bad news represented some of the challenges experienced when caring for the suddenly bereaved. The frequency to which participants were exposed to sudden death was most apparent in $A \& E$, with a nurse suggesting one per day following cardiac arrest. Participants were sensitive to the emotive situation and its impact on the family, other patients and staff. They claimed to have encountered an array of grief reactions, some more difficult to observe than others.

I wouldn't say there's a set reaction. I've literally had laughing ... to hysterics ... screaming ... blame ... every range of emotions. (I:04)

The mother and father attacked each other ... physically attacked each other in the relatives' room ... that was quite shocking to see ... (I:02)

Respecting the wishes of the bereaved family and their reactions to the news of a sudden death was apparent. However some found this challenging in the confines of the care environment, and perceived the need for mutual respect.

You try and accommodate as much as possible within the constraints of the unit. (l:06) 
... It's a two-way street. They [the family] have got to respect that are other patients as well ... (I:07)

\section{Perceived needs}

Participants were persistent in their perceptions of the families' need for information. Communication interventions comprised initial explanations, on-going updates and pre-planned meetings to promote family understanding of the end of life situation. Recollections of caring included examples of communication that sought to elicit the family's standpoint.

Normally the opening line is like 'What do you know?' ... That tells you their story. (I:04)

Is there any information you want to go through first with me, because I know the doctor has explained everything to you, but is there anything else you want to go over? (l:10)

Most information was communicated verbally, and participants were sensitive to issues such as clarity, timing, privacy, and the informant. The latter was particularly poignant in relation to conveying the news of a sudden death. One perspective was that the family might like to hear from the nurse with whom they have established a rapport, although in practice, a doctor appeared to be the main communicator. Some participants suggested a need to facilitate family understanding by repeating what the doctor had said in simpler terms. The norm was to avoid informing relatives of a death over the telephone, but honesty prevailed if the family asked outright. Written information (a bereavement booklet) explaining after death procedures was 
considered important for suddenly bereaved families who may find it difficult to retain verbal information.

At least they've got the booklet to refer to that tells you what the next step is, what to do ... I don't think they'd remember anything that you say. (I:04)

Facilities such as accommodation, access to a telephone and refreshments were identified comfort measures in response to perceived needs. The provision of a relatives' room was largely cited by participants working in A\&E and ICCU. This was referred to as a dedicated place for families. Some participants perceived families' preference for privacy, and suggested intermittent as opposed to constant nurse presence. Empathic gestures included privacy, the selective use of touch and listening.

His wife ... she was so upset and the only thing you could do at that point was to give her a hug. (I:07)

Sometimes you know, silence is golden ... Giving people time to let the information sink in and let them think about what they want to say. (I:10)

\section{Care provision}

Participants were respectful of families' preferences regarding presence with the dying person and at the time of death. Departmental guidelines about visiting times and the number of visitors at the bedside were relaxed. Practices such as family presence during resuscitation and when testing for brain-stem death implied choice, but facilitation seemed variable. Instances of family participation in decision-making concerned the withdrawal or withholding of treatment, do not attempt resuscitation (DNAR) and the potential for organ and tissue donation. There was an apparent undertone of 'talking to' families, but with a considerate intent. 
They [the family] have been broached. They have been made aware of it [DNAR] maybe days earlier. But you know, maybe something to think about ... (I:09)

Participants explained the need to complete essential tasks in the aftermath of a sudden death. Care interventions included preparation of the deceased for family viewing, performing last offices and handling personal property. Some nurses emphasised the importance of assessing the families' wishes and presenting options.

If they [the family] can deal with it, put it back to them and ask them what their wishes are at that moment in time. (I:10)

Participants were responsive to the religious and cultural requests of families, agreeing to contact chaplaincy services and obliging participation in care after death.

If they're Muslim religion, they like to do last offices with you, so they'll help you wash the body down. (I:06)

... An Asian family, they came in and wanted to wash the body in oil and that was fine, we allowed them to do that. (I:08)

\section{Beyond the event}

The humanism of caring was revealed when participants recalled the circumstances surrounding a sudden death. The emotional impact of caring for the suddenly bereaved was revealed and some participants remembered getting upset, particularly when families talked about their relationship with the dying or deceased person.

I've had situations where I've been in tears and the relative's mum has actually been comforting me ... A bizarre situation to be in, but they know you care. (I:06)

He [husband] was in his 90s ... They'd been together years and years and years ... She [wife] came in, CPR in progress and passed away ... He was crying and of course, I'd dealt with him so I was crying. (I:01) 
An ethos of caring support was evident among nursing colleagues and this included thoughtfulness for new and junior staff. Conversely, support after the event primarily comprised informal debriefing with colleagues, family and friends. There was a sense that the participants required and expected more, personally and professionally.

There's not really anything for nurses ... You've spent all day with this ... this one patient and then you walk out and you go home and that's it ... I don't know whether you can always give your best care when you ... It's just a horrible situation to be in. (I:02)

Participants referred to the turmoil of sudden bereavement and the potential for families to experience uncertainty and confusion. Families were given a contact number for the hospital bereavement suite and some nurses also provided the telephone number of the ward or department.

We can put our name on [the bereavement booklet] so they can ring back ... If they're worried about something, they know which one of us to call. (I:03)

For most, contact with the family ended at the point of their departure from the hospital. One participant recalled a time when families would receive a bereavement card, but this practice was no longer in place. A bereavement follow-up service for families was suggested; to provide explanations, resolve questioning, offer counselling and afford closure, and to obtain bereaved families' views about the care they received. Verbal expressions of gratitude, thank you cards and donations were received, but participants were conscious that these forms of feedback implied family satisfaction with care. There was a genuine desire for formal feedback.

We do what we do based on our experiences and nobody ever tells you; was it good? Was it bad? ... It would be really interesting to find out what relatives say ... To know what their feedback was and their experience. (I:08) 


\section{Influencing factors}

Contextual, professional and attitudinal factors influenced the degree to which personcentred care operated. Participants identified barriers to establishing nurse-family relationships, including the demands of caring for critically ill patients, the busy environment, manpower resources and the nature and brevity of the encounter. The impact of environmental pressures and associated dilemmas were revealed.

... A 90-year old woman who wants to tell you her husband's life story from start to finish ... If you could sit there and listen for as long as needed, but ... (l:02)

Establishing and maintaining a rapport with families was influenced by the organisation of care, shift patterns or personal choice to care for a different family. The emotional wellbeing of nurses took precedence at times.

I had a client on Wednesday and he died. So the next day they gave me another [dying patient] ... It seems like it's too much, I mean for me ... My shift leader said 'That allocation is not fair for you.' (I:05)

Participants acknowledged the gravity of EoLC decisions, but did not always appear comfortable about their own or the families' role and contribution. Some nurses identified professional conflict concerning medical decisions, and perceived this as having a negative impact on the quality of a trusting relationship.

I've gone in and spoke to the family with an anaesthetist and ... painted the worst picture ever... 'No they're not going to survive' ... And two days later the surgeon was in the room speaking to the family... and telling them a different story ... So for them [the family] it must be absolutely awful ... That would put doubt in the family's mind straight away, wouldn't it? (l:06)

Participants also experienced conflict due to governing processes and procedures. A bereaved family's request for invasive lines to be removed in a case of referral to the 
coroner served as an example of opposing nurse-family priorities. Some referred to their own personal experiences of dying and death, and care preferences if confronted with the same situation. This was seen to sway nurse-centred interventions.

Paternalistic attitudes also impacted on choice and facilitation.

If they [the family] don't broach the topic [participation in last offices] we tend to just get on with it, because sometimes that's not how you want to remember your loved one. You don't want to remember them like that. (I:07)

Participants reflected on nurses' skills and abilities to care for grieving families and the suddenly bereaved. It was suggested that some nurses avoided the situation, and were reluctant to partake in communicating the news of a sudden death. Some participants personally acknowledged a lack of experience and confidence, and the limits this placed on their contributions to care.

That's quite a big barrier. If you haven't got the experience and confidence to do it ... (I:07)

I don't think I'm anywhere near experienced enough to do anything like that. (l:02)

Formal education, role modelling, peer support and experiential learning were suggested methods of personal development.

\section{Discussion}

This aim of this study was to explore nursing interventions for person-centred bereavement care in adult acute and critical care settings. Participants' descriptions of care in situations of sudden death suggested individual motivation and commitment to practice in a person-centred way. Personal reflections on practice conveyed examples 
of dignity, compassion and respect; attributes deemed essential for the greater involvement of people in their own care and consistent with the personalisation agenda in health and social care (The Health Foundation, 2014).

Generally, the provision of care reflected what McCormack et al. (2011, p.1) referred to as 'person-centred moments.' Instances of personalised care materialised in participants' descriptions of care giving activities and in communication scenarios involving interpersonal interactions. A willingness to work with the person's beliefs and values was evidenced in participants' understanding of sudden death in keeping with the experiencing family interpretations. Some consideration was given to the families' expressed wishes and needs and examples of responsiveness suggested a sympathetic presence. Respecting individual customs and religious procedures following a death and providing opportunity to view the deceased are consistent with suddenly bereaved families' perceptions of helpful nursing actions (Li et al., 2002). Wright (1996) found that viewing the body after a sudden death was especially valued by relatives not present at the point of death, and more recent research reinforced the importance of preparation and informed choice (Chapple and Ziebland, 2010; Harrington and Sprowl, 2011; Mowll, 2007).

Communication was shown to be of central importance in this study. Participants' conveyed a genuine attempt to assist families' understanding through the giving and receiving of information, resulting in recognised opportunities for shared decisionmaking, participation and choice. In the study by Li et al. (2002), suddenly bereaved families ranked the provision of written information about what do following a death as the most helpful nursing action. Other studies have highlighted the importance of 
information for families of sudden death victims (Brysiewicz, 2008; Fanslow 1983; Fraser and Atkins, 1990; van der Klink et al., 2010), but also difficulties in information intake (Rejnö et al., 2013) and the potential need for information to be repeated several times (Dale et al., 2013).

Consistent with bereaved families' opinions (Brysiewicz, 2008; Fraser and Atkins, 1990), participants identified comfort measures as helpful to the suddenly bereaved. Simple gestures such as the offer of tea or asking if anything could be done to help were highly valued by families who had lost a loved one to a sudden death (Brysiewicz, 2008). The relatives' room appeared to be a shared facility, rather than the perceived helpfulness of a separate room for the bereaved family (Fraser and Atkins, 1990; Tye, 1993).

In contrast, there were occasions when routine practices, procedures and tasks prevailed or the values and beliefs of the care giver took precedence. These findings confirmed the coexistence of person-centred moments and nonperson-centred practices. Nurse-centric interventions were defended in the interests of the critically ill patient, the experiencing family and healthcare staff. The practical and psychological aspects of care appeared to take priority over other components of holistic care, such as the family's social and spiritual needs.

Participants identified barriers to establishing the nurse-family relationship and environmental pressures in particular appeared to create a dilemma of divided attentions. For example, participants would hear families' stories, but the valuing of this activity as part of person-centred care giving (McCormack and McCance, 2010) was delimited by competing demands. The suffering of the suddenly bereaved and a 
self-perceived lack of experience and skills also had a bearing on the level of nursefamily engagement, with distancing potentially operating as a form of personal defence. Scott (2013) suggested that many emergency nurses find it difficult to witness the distress of bereaved relatives. This is confirmed in research exploring the lived experiences of nurses who have provided EoLC in A\&E (Socorro et al., 2001) and within an intensive care unit (Holms et al., 2014; Stayt, 2009). Participants also identified what could be perceived as threats to staff-family relationships in situations of professional conflict, particularly around EoLC decisions in the ICCU. Participants' concerns were not unique; with all interviewees in the study by Holms et al. (2014) reporting episodes where a breakdown in communication caused mixed messages and inconsistencies in EoLC practices.

Participants appeared enthusiastic to obtain feedback on their performance and to utilise knowledge of bereaved families' experiences to benchmark their practice. However, it was apparent that the acute and critical care areas in this study did not have any established forms of follow-up. Brysiewicz (2008) argued that much could be done to improve the caring situation if healthcare professionals are made aware of the impact of their initial actions on the bereavement outcomes of families who experience a sudden death. Dale et al. (2013) agreed that nurses need knowledge of family experiences to inform the support they give to the suddenly bereaved.

Support for the nurse is also essential in the aftermath of a sudden death (Saines, 1997a, 1997b; Socorro et al., 2001). The emotional labour of caring has the potential to impact on nurses' wellbeing (Holms et al., 2014; Stayt, 2009) and their ability to provide quality care (Ryan and Seymour, 2013). An alleged lack of formal debrief in the 
clinical setting meant that participants in this study depended on the support of family and friends.

\section{Implications for the development of person-centred care}

The findings from the reported study have important implications for practice,

education and research. A person-centred approach to EoLC is not about doing more, but doing things differently in practice (Ball et al., 2013). Establishing a team philosophy of person-centred care could help to promote consistency in the experiences of suddenly bereaved families, both within and across the settings where sudden bereavement is known to occur. Improved continuity in care also requires a considered approach to the organisation and delivery of nursing care. The context of care must be taken into consideration, as situational and environmental factors can become a defence for paternalistic actions. Given that sudden death may have an adverse effect on post-bereavement outcomes (Parkes, 2010), it is plausible to suggest that the families' understanding of the situation and self-perceived needs are of upmost importance, rather than the nurses' interpretation. In the same way as McCormack and McCance (2010) argued that physical care can provide a focus for nurse-patient interaction, opportunities exist to personalise the nurse-family relationship when providing essential care after death. A dedicated role such as the positively evaluated trained support worker role in A\&E (Stone et al., 1999) could help to reconcile the conflict experienced by nurses by offering a solution to competing care demands. Concern for the emotional welfare of people who encounter sudden bereavement is applicable to both the recipients and providers of care. The study 
findings infer that wellbeing may be enhanced by the provision of immediate and longer-term support. The satisfaction to be gained from further contact could be mutually felt through a programme of follow-up with bereaved families (Downar et al., 2014; Rodger et al., 2006; Williams et al., 2003). Likewise, debriefing sessions could help nurses to reflect on the feelings they experienced while caring for suddenly bereaved families and give closure to the events (Socorro et al., 2001).

A combination of formal education and experiential learning are essential to developing nurses' confidence and competence in caring for the suddenly bereaved, and in challenging personal attitudes, suppositions and beliefs. A strategy advocated by Coombs (2013) is to see expertise in action by creating opportunities to observe credible role models in practice. However, practice also needs to be underpinned by knowledge and understanding of what is known about EoLC (Coombs, 2013). The findings of a study by Rodger et al. (2006) reinforced the need for on-going education to increase awareness of the support needs of the suddenly bereaved person. Workshops involving simulation could be beneficial in developing nurses' communication skills and their ability to cope with family and personal reactions. Educators should prepare learners for the potential to experience differing grief reactions in situations of sudden and unexpected death. The teaching and learning of person-centred care is also essential to developing and improving the personcentredness of the families' bereavement care experience.

Sudden death and bereavement warrants further attention in the literature and could be made more explicit in the objectives of EoLC research. Developing a robust evidence-base for practice requires further understanding of the experiences and 
outcomes of personalisation from the perspectives of the suddenly bereaved and wider members of the health care team. Achieving the aims of a personalisation agenda is also reliant on contextual data that can be used to drive micro-system improvement (Wood et al., 2015) for example, at the level of a unit, department or ward team. Rattray and McKenna (2012) recognised the value of both qualitative and quantitative approaches to research; the former to support continuous improvements in person-centred care at a local level and the latter affording opportunity to benchmark and compare study findings when working with larger data sets. Fridh (2014) argued a reliance on the opinions of close relatives to reveal the quality and significance of nursing care. Bereavement follow-up services afford a dual mechanism for providing and obtaining essential feedback concerning the families' experiences of care (Brysiewicz et al., 2008; Cuthbertson et al., 2000; Stone et al. 1999).

\section{Study strengths and limitations}

Consistent with techniques for enhancing the trustworthiness of qualitative inquiry (Lincoln and Guba, 1985), the research process was made explicit to allow readers to judge the credibility and dependability of the study. Participant quotations were provided to support analytic claims and reference to existing research helped to confirm the validity of interpretations. The fact that the study took place in one hospital in the UK with a small purposive sample of RNs may limit transferability of the findings to other contexts. A purposive sample of RNs was identified from the target population to support the recruitment process, and those who agreed to join the study did so by virtue of self-selection. The potential bias associated with a predetermined, 
volunteer sample is acknowledged, as is the differing educational preparation, clinical expertise and role of the non-registered nurse participant. Additional care was taken during analyses and reporting to avoid representation of a lone voice or viewpoint that could threaten the validity of the study findings. The inherent bias of the researchers' personal and professional experiences of sudden death is also recognised. Conversely, prior knowledge and understanding of the context of care facilitated a positive rapport during the interview encounter, and a rich description of participants' experiences of care for the suddenly bereaved.

\section{Conclusion}

A person's sudden death is a devastating, life-changing experience for families and a highly emotive situation for the nurses involved. This study, while limited in terms of sample-size, importantly adds to the small collection of research available on the topic of sudden death and bereavement. The findings provided insight into the provision of person-centred care for suddenly bereaved families, and the barriers to achieving a person-centred approach. Caring for suddenly bereaved families in a person-centred way was important to nurses, but also a source of tension and unrest. A key consideration for person-centred practice is movement away from sudden bereavement as a 'here and now' event, towards a pathway of supportive care that envisions the longer-term. In the spirit of person-centredness, members of the health care team and suddenly bereaved families have an essential and equal role to play in developing and defining a robust body of knowledge for person-centred care in adult acute and critical settings. 


\section{Acknowledgements}

We would like to thank Divisional Matrons for facilitating the participant identification and recruitment process and the study participants for their valuable contribution at interview. We also acknowledge funding support from the University of Wolverhampton Early Researcher Award Scheme.

\section{References}

Ball P, Monks N, Torkington A, Meyerhoff T, Sanderson H. Progress for Providers End of Life: Checking your progress in delivering personalised support at end of life. Cheshire: HSA Press; 2013.

Brysiewicz, P. The lived experience of losing a loved on to a sudden death in KwaZuluNatal, South Africa. J Clin Nurs 2008; 17: 224-31.

Chapple A, Ziebland S. Viewing the body after bereavement due to a traumatic death: qualitative study in the UK. Br Med J 2010; 340: c2032.

http://dx.doi.org/10.1136/bmj.c2032

Coombs M. Yes, but how do I know what I don't know? Moving towards conscious competence in end-of-life care. Nurs Crit Care 2013; 18(5): 217-8.

Cuthbertson SJ, Margetts MA, Streat SJ. Bereavement follow-up after critical illness. Crit Care Med 2000; 28(4): 1196-201. 
Dale D, Mayer M, Rosenfeld AG, Gilbert K. Lives forever changed: Family bereavement experiences after sudden cardiac death. Appl Nurs Res 2013; 26: 168-73.

Department of Health. End of life care strategy: Promoting high quality care for all adults at the end of life. London: DH; 2008.

Department of Health. Personalisation through Person-Centred Planning. London: DH; 2010.

Department of Health. Health and Social Care Act. London: DH; 2012.

Deranieri JT, Clements PT, Henry GC. When catastrophe happens. Assessment and intervention after sudden traumatic death. J Psychosoc Nurs Ment Health Serv 2002; 40(4): 30-7.

Downar J, Barua R, Sinuff T. The desirability of an intensive care unit (ICU) clinician-led bereavement screening and support program for family members of ICU decedents (ICU bereave). J Crit Care 2014; 29(311):e9-16.

Fanslow J. Needs of grieving spouse in sudden death situations: a pilot study. J Emerg Nurs 1983; 9(4): 213-6. 
Fraser S, Atkins J. Survivors' recollections of helpful and unhelpful emergency nurse activities surrounding sudden death of a loved one. J Emerg Nurs 1990; 16(1): 13-6.

Fridh I. Caring for the dying patient in the ICU - The past, the present and the future. Intensive Crit Care Nurs 2014; 30: 306-11.

Harrington C, Sprowl B. Family members' experiences with viewing in the wake of sudden death. OMEGA 2011; 64(1): 65-82.

Holms N, Milligan S, Kydd A. A study of the lived experiences of registered nurses who have provided end-of-life care within an intensive care unit. Int J Palliat Nurs 2014; 20(11): 549-56.

Hsieh H-F, Shannon SE. Three approaches to qualitative content analysis. Qual Health Res 2005; 15(9): 1277-88.

Kent $\mathrm{H}$, McDowell J. Sudden bereavement in acute care settings. Nurs Stand 2004; 19(6): 38-42.

Leadbeater C, Garber J. Dying for Change. London: Demos; 2010. 
Leadership Alliance for the Care of Dying People. One change to get it right: improving people's experience of care in the last few days and hours of life. London: LACDP; 2014.

Li SP, Chan CWH, Lee DTF. Helpfulness of nursing actions to suddenly bereaved family members in an accident and emergency setting in Hong Kong. J Adv Nurs 2002; 40(2): $170-80$.

Lincoln YS, Guba EG. Naturalistic inquiry. Beverly Hills, CA: Sage Publications; 1985.

Marshall C, Rossman GB. Designing Qualitative Research. 3rd ed. Thousand Oaks, CA: Sage Publications; 1999.

McCormack B, McCance T. Person-Centred Nursing: Theory and Practice. Oxford: Wiley-Blackwell; 2010.

McCormack B, Dewing D, McCance T. Developing person-centred care: Addressing contextual challenges through practice development. Online J Issues Nurs 2011, http://www.nursingworld.org/MainMenuCategories/ANAMarketplace/ANAPeriodicals /OJIN/TableofContents/Vol-16-2011/No2-May-2011/Developing-Person-CentredCare.aspx [accessed 01.11.15]. 
Mowll J. Reality and regret: Viewing or not viewing the body after a sudden death. Bereave Care 2007; 26(1): 3-6.

Myerburg RJ, Wellens HJJ. Epidemiology of cardiac arrest. In: Priori S, Zipes D, editors. Sudden Cardiac Death: A Handbook for Clinical Practice. Oxford Blackwell Publishing; 2005. p. 3-20.

NHS Employers. How Agenda for Change works. London: NHS Employers; 2015, http://www.nhsemployers.org/your-workforce/pay-and-reward/pay/agenda-forchange-pay/how-agenda-for-change-works [accessed 01.11.15].

National Institute for Health and Care Excellence (NICE). Quality standard for end of life care for adults; 2011; http://www.nice.org.uk/guidance/qs13 [accessed 01.11.15]

Parkes CM. Grief: lessons from the past, visions for the future. Psychol Belg 2010; $50(1 \& 2): 7-26$.

Purves $\mathrm{Y}$, Edwards S. Initial needs of bereaved relatives following sudden and unexpected death. Emerg Nurse 2005; 13(7): 28-34.

Rattray J, McKenna E. Person-centred care in intensive care: a myth or reality. Nurs Crit Care 2012; 17(5): 225-6. 
Rejnö A, Danielson E, Berg L. Next of kin's experiences of sudden and unexpected death from stroke - a study of narratives. BMC Nurs 2013, http://bmcnurs.biomedcentral.com/articles/10.1186/1472-6955-12-13 [accessed 26.01.16]

Rodger ML, Sherwood P, O'Connor M, Leslie G. Living beyond the unanticipated sudden death of a partner: A phenomenological study. OMEGA 2006; 54(2): 107-33.

Ryan L, Seymour J. Death and dying in intensive care: Emotional labour of nurses. End of Life J 2013; 3(2): 1-9.

Saines JC. Phenomenon of sudden death: Part 1. Accid Emerg Nurs 1997a; 5: 164-71.

Saines JC. Phenomenon of sudden death: Part 2. Accid Emerg Nurs 1997b; 5: 205-9.

Scott T. Sudden death in emergency care: responding to bereaved relatives. Emerg Nurse 2013; 21(8): 36-9.

Socorro LL, Tolson D, Fleming V. Exploring Spanish emergency nurses' lived experience of the care provided for suddenly bereaved families. J Adv Nurs 2001; 35(4): 562-70.

Stayt LC. Death, empathy and self preservation: the emotional labour of caring for families of the critically ill in adult intensive care. J Clin Nurs 2009; 18(9): 1267-75. 
Stone G, Huggon A-M, Nayeem N. Telephone follow-up of relatives after sudden death: A survey of relatives' views. Int J Clin Pract 1999; 53(2): 107-9.

The Health Foundation. Person-centred care made simple. London: The Health Foundation; 2014, www.health.org.uk/publications/person-centred-care-made-simple [accessed 01.11.15]

The National Council for Palliative Care. Life after death: Six steps to improve support in bereavement. London: NCPC; 2014.

Tye C. Qualified nurses' perceptions of the needs of suddenly bereaved family members in the accident and emergency department. J Adv Nurs 1993; 18: 948-56.

van der Klink MA, Heijboer L, Hofhuis JGM, Hovingh A, Rommes JH, Westerman MJ. et al. Survey into bereavement of family members of patients who died in the intensive care unit. Intensive Crit Care Nurs 2010; 26: 215-25.

Walker WM. Sudden cardiac death in adults: causes, incidence and interventions. Nurs Stand 2010; 24(38):50-6.

Williams R, Harris S, Randall L, Nichols R, Brown S. A bereavement after-care service for intensive care relatives and staff: the story so far. Nurs Crit Care 2003; 8(3): 109-15. 
Wood S, Collins A, Taylor A. Is the NHS becoming more person-centred? London: The Health Foundation; 2015, http://www.health.org.uk/sites/default/files/IsTheNHSBecomingMorePersonCentred. pdf [accessed 01.11.15].

Worden JW. Grief Counselling and Grief Therapy: A Handbook for the Mental Health Practitioner. 4th ed. New York: Springer Publishing Company; 2009.

Wright B. Sudden Death: A research base for practice. 2nd ed. Edinburgh: Churchill Livingstone; 1996.

Zipes DP, Wellens HJJ. Sudden cardiac death. Circulation 1998; 98: 2334-51. 


\section{Implications for Clinical Practice}

- The concepts of dignity, compassion and respect characterise the presence of personcentred bereavement care in practice.

- Caring for suddenly bereaved families in a person-centred way was important to acute and critical care nurses, but ambivalence was also felt.

- A combination of formal education and experiential learning are essential to developing nurses' confidence and competence to care for the suddenly bereaved.

- Further research is needed to determine the outcomes of person-centred nursing care. Bereaved families' experiences are an important marker of quality care. 